\title{
Korelasi antara Skor Intracerebral Hemorrhage (ICH) dengan Mortalitas Pasien Perdarahan Intraserebral di RSUD Ulin Banjarmasin
}

\author{
Marini Awanis $^{*}$, Kenanga M. Sikumbang ${ }^{* *}$, Asnawati $\left.^{* * *}\right)$ \\ "Fakultas Kedokteran Universitas Lambung Mangkurat, ${ }^{* *}$ Departemen Anestesiologi dan Terapi Intensif, Fakultas \\ Kedokteran, Universitas Lambung Mangkurat-RSUD Ulin Banjarmasin, ${ }^{* * *}$ Departemen Biomedik, Fakultas \\ Kedokteran, Universitas Lambung Mangkurat
}

\begin{abstract}
Abstrak
Latar Belakang dan Tujuan: Perdarahan intraserebral (PIS) merupakan kejadian medis yang meningkatkan angka kematian dan kecacatan tinggi. Secara teori, mortalitas PIS dapat diprediksi dengan menggunakan komponen skor Intracerebral Hemorrhage (ICH). Tujuan penelitian ini untuk mengetahui bagaimana korelasi antara skor ICH dengan mortalitas pasien PIS di RSUD Ulin Banjarmasin.

Subjek dan Metode: Penelitian ini bersifat observasional analitik dengan pendekatan cross sectional. Sebanyak 53 sampel didapatkan secara consecutive sampling. Data hasil penelitian diuji dengan uji Regresi Logistik.

Hasil: Dalam penelitian ini pasien skor ICH 0 meninggal sebanyak 15\%, 36\% skor ICH 1, 71\% skor ICH 2, 86\% skor ICH 3 dan 100\% skor ICH 4 dan 5. Hasil analisis data penelitian ini, diperoleh OR $=0,02 ; 0,06 ; 0,3$ untuk masing-masing skor ICH 1, 2 dan $\geq 3$; dengan $\mathrm{p}=0,001$.

Simpulan: Terdapat korelasi yang sangat signifikan dan hubungan positif antara skor ICH dengan mortalitas pasien PIS di RSUD Ulin Banjarmasin, sebagai prediktor independen.
\end{abstract}

Kata kunci: perdarahan intraserebral, skor ICH, prediktor, mortalitas

JNI 2021; 10 (1): 1-7

\section{Correlation between ICH Score with ICH Patient's Mortality at Ulin General Hospital Banjarmasin}

\begin{abstract}
Background and Objective: Intracerebral hemorrhage (ICH) is the medical events that increases the mortality and disability. Theoretically, mortality can be predict by ICH score's components. The purpose of this study is to determine the correlation between ICH scores and mortality of ICH patients in Ulin General Hospital Banjarmasin. Subject and Method: This research is an analytic observational with cross sectional approach. A total of 53 samples were obtained by consecutive. Data analysis of this study used the Logistic Regression test.

Result: In this study, it was found that patients with ICH score 0 died $15 \%, 36 \%$ score $1,71 \%$ score $2,86 \%$ score 3 and $100 \%$ score 4 and 5 . Data analysis of this study showing OR=0,02;0,06; 0,3 for ICH score 1,2 and $\geq 3$ respectively; with $\mathrm{p}=0,001$.

Conclusion: There is a very significant correlation and enough positive relationship between the ICH score and mortality of ICH patients in Ulin General Hospital Banjarmasin, as independent predictor.
\end{abstract}

Key words: intracerebral hemorrhage, ICH score, predictor, mortality

JNI 2021; 10 (1): 1-7

This article is licensed under a

Creative Commons Attribution-NonCommercial-ShareAlike 4.0 International License.

CMarini Awanis, Kenanga M. Sikumbang, Asnawati

(2021) under the CC-BY-NC-SA license 


\section{Pendahuluan}

Perdarahan intraserebral (PIS) menjadi penyumbang kejadian stroke hingga $10-20 \%$. Dilaporkan, terdapat 2 juta kasus PIS terjadi setiap tahunnya di dunia. Pada negara barat seperti Amerika Serikat, Inggris dan Australia, kejadian PIS berkisar $8-5 \%$, sedangkan di Jepang dan Korea 18-24\%. Data di tahun 2010 menyebutkan per 100.000 kejadian PIS, 5,9\% berusia $35-54$ tahun, $37,2 \%$ berusia $55-74$ tahun dan $176,3 \%$ berusia 75-94 tahun. Berdasarkan jenis kelamin, laki-laki lebih tinggi dibandingkan perempuan, terutama pada PIS sekunder atau traumatik. ${ }^{1,2}$ Dilihat dari tingkat mortalitasnya, PIS merupakan tipe stroke yang paling mematikan, dengan angka mortalitas dalam 30 hari berkisar hingga $40 \%{ }^{3}$

Kejadian PIS disebabkan karena pecahnya pembuluh darah kecil di otak, baik secara spontan maupun dikarenakan trauma. Adanya hematoma memberikan efek massa dan peningkatan tekanan intrakranial, dan menimbulkan kerusakan anatomis pada otak dan sekitarnya. Adapun efek toksisitas dari darah dan faktor-faktor inflamasi yang keluar bersamaan menimbulkan cedera sekunder pada jaringan otak, memicu terjadinya kematian sel otak. ${ }^{4}$ Tingginya tingkat mortalitas pada kasus PIS ini menjadikannya sebagai salah satu kejadian medis yang paling mematikan. ${ }^{5}$ Mortalitas pasien sederhananya dapat dibagi menjadi meninggal atau tidak meninggal. Adapun penilaian fungsional dapat diukur dengan beberapa skala, salah satunya glasgow outcome scale (GOS), yang mengklasifikasikan luaran pasien yang mengalami cedera pada jaringan otak. ${ }^{2,3}$ Sedangkan cara dalam memprediksi mortalitas pasien PIS di antara menggunakan skor Intracerebral Hemorrhage (ICH), skor ICH Essen, ICH-FOS, skor FUNC dan skor AVICH. Namun, karena keterbatasan penelitian maupun validitas, skor ICH merupakan cara yang paling mudah dan tepat. ${ }^{6}$

Skor ICH dikemukakan sebagai salah satu alat untuk memprediksi mortalitas pasien PIS. Skor ini memudahkan menentukan prognosis, semakin tinggi skor yang didapat maka semakin berisiko mengalami kematian dalam 30 hari. Komponen skor ICH mempertimbangkan usia, skor GCS dan gambaran radiologis perdarahan yang diambil dalam waktu 24 jam setelah kedatangan pasien, ketika kondisi pasien telah stabil. ${ }^{7,8}$ Dari uraian di atas, dapat diketahui bahwa insiden kasus PIS cukup banyak dan tingkat mortalitasnya yang cukup tinggi. Namun belum ada penelitian mengenai analisis korelasi skor ICH dengan mortalitas pasien PIS di RSUD Ulin Banjarmasin. Oleh karena itu, penelitian ini dilakukan untuk mengetahui bagaimana korelasi skor ICH dengan mortalitas pasien PIS di RSUD Ulin Banjarmasin.

\section{Subjek dan Metode}

Rancangan penelitian yang digunakan adalah observasional analitik dengan pendekatan cross sectional. Populasi dalam penelitian ini adalah seluruh pasien PIS yang masuk RSUD Ulin Banjarmasin selama bulan JuliOktober 2019. Sampel penelitian ini adalah pasien PIS selama bulan Juli-Oktober 2019 yang memenuhi kriteria inklusi dan eksklusi. Teknik pengambilan sampel dilakukan dengan metode consecutive sampling. Sampel penelitian ini minimal berjumlah 32 orang berdasarkan tabel Isaac dan Michael dengan populasi berjumlah 35 pasien dan tingkat kesalahan 5\%. Kriteria inklusi untuk sampel dalam penelitian ini adalah 1) Pasien PIS spontan/non traumatik. 2) Pasien PIS dengan usia $\geq 18$ tahun. Kriteria eksklusi untuk sampel dalam penelitian ini adalah pasien PIS berulang. Pengambilan data dilakukan dengan menentukan skor ICH oleh peneliti pada pasien PIS di IGD, Bangsal Saraf dan Stroke Center RSUD Ulin Banjarmasin dalam rentang waktu 24 jam setelah kedatangan pasien, setelahnya diambil data mortalitas pasien pada saat keluar rumah sakit atau selambat-lambatnya 30 hari sejak pasien mengalami kejadian PIS. Data yang diperoleh kemudian dilakukan uji analisis dengan pendekatan model prediksi yang berskala dikotomi, menggunakan korelasi nonparametrik regresi logistik.

\section{Hasil}

Pasien PIS di RSUD Ulin Banjarmasin dalam 
Tabel 1. Karakteristik Data Demografi

\begin{tabular}{|c|c|c|}
\hline \multirow[t]{2}{*}{ Karakteristik } & \multicolumn{2}{|c|}{ Jumlah } \\
\hline & $\mathrm{n}$ & $\%$ \\
\hline \multicolumn{3}{|l|}{ Jenis kelamin } \\
\hline Laki-laki & 31 & 58 \\
\hline Perempuan & 22 & 42 \\
\hline \multicolumn{3}{|l|}{ Lokasi perdarahan } \\
\hline Ganglia basalis & 23 & 43 \\
\hline Lobar & 22 & 42 \\
\hline Batang otak & 7 & 13 \\
\hline Serebelum & 1 & 2 \\
\hline \multicolumn{3}{|l|}{ Usia } \\
\hline$<55$ tahun & 26 & 49 \\
\hline$\geq 55$ tahun & 27 & 51 \\
\hline \multicolumn{3}{|l|}{ GCS } \\
\hline $3-4$ & 0 & 0 \\
\hline $5-12$ & 34 & 64 \\
\hline $13-15$ & 19 & 36 \\
\hline \multicolumn{3}{|c|}{ Volume perdarahan (cc) } \\
\hline$<30$ & 35 & 66 \\
\hline$\geq 3$ & 18 & 34 \\
\hline \multicolumn{3}{|c|}{$\begin{array}{l}\text { Perdarahan intraventri- } \\
\text { kular }\end{array}$} \\
\hline $\mathrm{Ya}$ & 17 & 32 \\
\hline Tidak & 36 & 68 \\
\hline \multicolumn{3}{|l|}{ Lokasi infratentorial } \\
\hline Ya & 8 & 15 \\
\hline Tidak & 45 & 85 \\
\hline \multicolumn{3}{|l|}{ Terapi } \\
\hline Operatif & 13 & 25 \\
\hline Konservatif & 40 & 75 \\
\hline \multicolumn{3}{|l|}{ Skor ICH } \\
\hline 0 & 13 & 26 \\
\hline 1 & 14 & 27 \\
\hline 2 & 15 & 29 \\
\hline 3 & 7 & 14 \\
\hline 4 & 1 & 2 \\
\hline 5 & 1 & 2 \\
\hline 6 & 0 & 0 \\
\hline \multicolumn{3}{|l|}{ Mortalitas } \\
\hline Hidup & 26 & 49 \\
\hline Meninggal & 27 & 51 \\
\hline
\end{tabular}

Tabel 2. Distribusi Skor ICH dan Mortalitas Pasien PIS Berdasarkan Tindakan Terapi.

\begin{tabular}{|c|c|c|c|c|c|}
\hline \multirow{3}{*}{$\begin{array}{l}\mathrm{S} \mathrm{k} \text { o r } \\
\mathrm{ICH}\end{array}$} & \multicolumn{4}{|c|}{ Konservatif } & \multirow{3}{*}{$\begin{array}{c}\text { Total } \\
\mathrm{n}\end{array}$} \\
\hline & \multicolumn{2}{|c|}{ Hidup } & \multicolumn{2}{|c|}{ Meninggal } & \\
\hline & $\mathrm{n}$ & $\%$ & $\mathrm{n}$ & $\%$ & \\
\hline 0 & 11 & 85 & 2 & 15 & 13 \\
\hline 1 & 6 & 55 & 5 & 45 & 11 \\
\hline 2 & 4 & 33 & 8 & 67 & 12 \\
\hline 3 & 0 & 0 & 3 & 100 & 3 \\
\hline 4 & 0 & 0 & 0 & 0 & 0 \\
\hline 5 & 0 & 0 & 1 & 100 & \\
\hline Total & 21 & & 19 & & 40 \\
\hline \multirow{3}{*}{$\begin{array}{c}\mathrm{S} \mathrm{k} \text { o r } \\
\mathrm{ICH}\end{array}$} & \multicolumn{4}{|c|}{ Operatif } & Total \\
\hline & \multicolumn{2}{|l|}{ Hidup } & \multicolumn{2}{|c|}{ Meninggal } & $\mathrm{n}$ \\
\hline & $\mathrm{n}$ & $\%$ & $\mathrm{n}$ & $\%$ & \\
\hline 0 & 0 & 0 & 0 & 0 & 0 \\
\hline 1 & 3 & 100 & 0 & 0 & 3 \\
\hline 2 & 1 & 20 & 4 & 80 & 5 \\
\hline 3 & 1 & 25 & 3 & 75 & 4 \\
\hline 4 & 0 & 0 & 1 & 100 & 1 \\
\hline 5 & 0 & 0 & 0 & 0 & 0 \\
\hline Total & 5 & & 8 & & 13 \\
\hline
\end{tabular}

Tabel 3. Data Hasil Penelitian Skor ICH dengan Mortalitas Pasien PIS di RSUD Ulin Banjarmasin.

\begin{tabular}{lll}
\hline Skor ICH & Hidup $(\mathrm{n})$ & Meninggal(n) \\
\hline 0 & $11(85 \%)$ & $2(15 \%)$ \\
1 & $9(64 \%)$ & $5(36 \%)$ \\
2 & $5(29 \%)$ & $12(71 \%)$ \\
3 & $1(14 \%)$ & $6(86 \%)$ \\
4 & $0(0 \%)$ & $1(100 \%)$ \\
5 & $0(0 \%)$ & $1(100 \%)$ \\
\hline
\end{tabular}

periode Juli-Oktober 2019 didapatkan 78 pasien dengan 57 subjek penelitian yang memenuhi kriteria inklusi (Tabel 1). Hasil uji analisis antara skor ICH dengan mortalitas (Tabel 2) didapatkan korelasi yang signifikan dengan nilai $p=0,001$ atau $\mathrm{p}<0,05$. Berdasarkan masing-masing odds ratio diperoleh hubungan dengan arah positif. Pasien dengan skor ICH 1 akan meningkatkan risiko mortalitas pasien PIS sebanyak 0,02 kali 
Tabel 4. Uji Analisis Korelasi Skor ICH dengan Mortalitas Pasien PIS di RSUD Ulin Banjarmasin

\begin{tabular}{lllll}
\hline $\begin{array}{l}\text { Skor } \\
\text { ICH }\end{array}$ & Mortalitas & Total & P & $\begin{array}{l}\text { OR } \\
(95 \% \text { C.I })\end{array}$
\end{tabular}

\begin{tabular}{|c|c|c|c|c|c|c|}
\hline & Hidup & Meninggal & & & & \\
\hline 0 & 11 & 2 & 13 & \multirow{6}{*}{0,001} & & \multirow{6}{*}{0,369} \\
\hline 1 & 9 & 5 & 14 & & 0,023 & \\
\hline 2 & 5 & 12 & 17 & & 0,069 & \\
\hline 3 & 1 & 6 & 7 & & & \\
\hline 4 & 0 & 1 & 1 & & 0,300 & \\
\hline 5 & 0 & 1 & 1 & & & \\
\hline Total & 26 & 27 & 53 & & & \\
\hline
\end{tabular}

Ket: Data disajikan dalam bentuk ordinal-nominal. Uji statistik menggunakan regresi logistik. Bermakna jika nilai $\mathrm{p}<0,05$.

Tabel 5. Uji Analisis Hubungan Skor ICH dengan Terapi Pasien PIS di RSUD Ulin Banjarmasin

\begin{tabular}{|c|c|c|c|c|c|c|c|c|}
\hline \multirow{3}{*}{$\begin{array}{l}\text { Skor } \\
\text { ICH }\end{array}$} & \multicolumn{4}{|c|}{ Terapi } & \multirow[t]{2}{*}{ Total } & \multirow[t]{2}{*}{$\mathrm{P}$} & \multirow{3}{*}{$\begin{array}{l}\text { OR } \\
(95 \% \text { C.I })\end{array}$} & \multirow[t]{3}{*}{ Nagelkerke R Square } \\
\hline & \multicolumn{2}{|c|}{ Konservatif } & \multicolumn{2}{|c|}{ Operatif } & & & & \\
\hline & $\mathrm{n}$ & $\%$ & $\mathrm{n}$ & $\%$ & & \multirow{7}{*}{0,009} & & \\
\hline 0 & 13 & 100 & 0 & 0 & 13 & & & \multirow{6}{*}{0,291} \\
\hline 1 & 11 & 79 & 3 & 11 & 14 & & 0,000 & \\
\hline 2 & 12 & 71 & 5 & 29 & 17 & & 0,218 & \\
\hline 3 & 3 & 43 & 4 & 57 & 7 & & & \\
\hline 4 & 0 & 0 & 100 & 1 & 1 & & 0,333 & \\
\hline 5 & 1 & 100 & 0 & 0 & 1 & & & \\
\hline Total & 26 & & 27 & & 53 & & & \\
\hline
\end{tabular}

Tabel 6. Uji Analisis Hubungan Terapi dengan Mortalitas Pasien PIS di RSUD Ulin Banjarmasin

\begin{tabular}{lllllll}
\hline Terapi & \multicolumn{2}{l}{ Hidup } & \multicolumn{2}{l}{ Meninggal } & Total & $\mathrm{P}$ \\
& $\mathrm{n}$ & $\%$ & $\mathrm{n}$ & $\%$ & & \\
\hline Konservatif & 21 & 53 & 19 & 47 & 40 & 0,379 \\
Operatif & 5 & 38 & 8 & 62 & 13 & \\
\hline
\end{tabular}

Ket: Data disajikan dalam bentuk nominal-nominal. Uji statistik menggunakan chi square. Bermakna jika nilai $\mathrm{p}<0,05$.

lipat dibandingkan dengan skor ICH 0. Pasien dengan skor ICH 2 akan mengalami peningkatan 0,06 kali lipat dan pasien dengan skor ICH $\geq 3$ setidaknya mengalami peningkatan risiko sebanyak 0,3 kali lipat. Sekitar 34,3\% skor ICH mempengaruhi variabel mortalitas. Sedangkan sisanya sebesar 65,8\% kemungkinan disebabkan adanya pengaruh penyakit penyerta yang dialami pasien, dan/atau tindakan terapi yang diberikan pada pasien.

\section{Pembahasan}

Berdasarkan tabel 1, pasien laki-laki lebih banyak dibandingkan pasien perempuan. Penelitian lain juga menyatakan perbandingan yang serupa, terutama pada usia di bawah 80 tahun di populasi multi-etnik Asia. Hal ini berkaitan dengan tekanan darah diastolik pada perempuan yang lebih rendah dan hormon yang cenderung memiliki efek neuroprotektif. Namun penyebab 
dan konsekuensi lebih lanjut sehubungan dengan progres kejadian PIS masih belum jelas. ${ }^{9}$

Distribusi berdasarkan lokasi perdarahan tertinggi di ganglia basalis, diikuti dengan lobar, batang otak dan serebelum. Penelitian lain juga mendapatkan lokasi PIS didominasi di bagian ganglia basalis. ${ }^{10}$ Perdarahan intraserebral bagian dalam (non lobar) dihasilkan dari pecahnya pembuluh arteri kecil yang berpenetrasi di parenkim otak. Kondisi ini terutama diakibatkan oleh adanya perubahan degeneratif pada dinding pembuluh darah yang berhubungan erat dengan peningkatan usia, hipertensi kronik, diabetes dan faktor risiko lainnya yang berkaitan dengan pembuluh darah. Adapun pada perdarahan di bagian lobar berkaitan dengan kondisi cerebral amyloid angipathy (CAA) yang mengakibatkan adanya deposit amiloid beta peptida di dinding pembuluh daah kecil dan mempermudah terjadinya pecahnya dinding pembuluh darah. ${ }^{5}$

Hasil penelitian ini menunjukkan bahwa pasien PIS lebih banyak terjadi pada pasien dengan usia $<80$ tahun dan hanya 1 kasus pasien PIS dengan usia $\geq 80$ tahun. Penelitian di RSUD Prof. Dr. Margono Soekarjo Purwokerto yang juga didapatkan kejadian PIS terbanyak pada rentang 50-59 tahun, sedangkan pada rentang 80-89 tahun hanya 4 kasus. ${ }^{11}$ Hal ini berkaitan dengan adanya kondisi hipertensi yang terjadi di usia lebih muda terutama di negara Asia ditambah lagi dengan deteksi dini yang terlambat dan penggunaan obat yang tidak teratur. ${ }^{12}$ Mayoritas kasus PIS memiliki skor GCS 5-12. Serupa dengan penelitian di RSUP H. Adam Malik Medan dan penelitian di Makassar. ${ }^{13,14}$ Volume perdarahan pasien PIS lebih banyak yang kurang dari $30 \mathrm{cc}$. Beberapa studi mendapatkan hal serupa meski perbedaannya tidak terlalu jauh. ${ }^{14,15}$ Adapula variasi insidens yang mendapatkan sebaliknya. ${ }^{13}$

Pasien yang tidak disertai perdarahan intraventrikulardantidakberasal dariinfratentorial lebih banyak jumlahnya. Satu penelitian menyatakan kejadian perdarahan intraventrikular erat kaitannya dengan usia yang lebih tua dan lokasi perdarahan yang lebih dalam. ${ }^{16}$ Rincian distribusi frekuensi skor ICH pada penelitian ini memiliki rentang nilai skor ICH 0 sampai 5 dan tidak ada data pasien dengan skor 6. Proporsi pasien meningkat sebanding dengan kenaikan skor ICH, hingga mencapai proporsi tertinggi di skor ICH 2, lalu menurun drastis setelahnya. Hal ini disebabkan karena frekuensi pasien PIS yang berusia $\geq 80$ tahun dan lokasi perdarahan di infratentorial jauh lebih sedikit dibandingkan parameter yang lain, sehingga sulit mendapatkan variasi pasien dengan skor 4 sampai 6 . Pasien PIS yang meninggal saat keluar rumah sakit atau paling lama 30 hari setelah onset sedikit lebih banyak dibandingkan pasien yang meninggal.

Secara deskriptif hubungan antara skor ICH dengan mortalitas pasien PIS (Tabel 3), didapatkan adanya peningkatan angka kematian pasien yang sebanding dengan kenaikan skor ICH pasien. Akan tetapi terdapat pasien meninggal dengan skor ICH 0 dan 1 . Hal ini terkait dengan usia pasien yang lebih dari 70 tahun, namun belum memenuhi indikator komponen usia $(\geq 80)$, padahal menurut Badan Pusat Statistik angka harapan hidup di Kalimantan Selatan ialah 70,17 tahun. ${ }^{17}$ Penelitian di India melaporkan adanya perbedaan signifikan modifikasi rentang usia dalam penggunaan skor ICH, yakni pasien dibawah usia 70 tahun memiliki tingkat kematian secara signifikan lebih rendah (29\%) dibandingkan yang $\geq 70$ tahun. ${ }^{12}$ Selain itu juga adanya kemungkinan penyakit penyerta berupa hipertensi yang tidak terkontrol, diabetes atau kondisi lain yang tidak terdata.

Berdasarkan analisis (Tabel 4) diperoleh hubungan dengan arah positif, pasien dengan skor ICH 1 akan meningkatkan risiko mortalitas pasien PIS sebanyak 0,02 kali lipat dibandingkan pasien dengan skor ICH 0. Pada pasien dengan skor ICH 2 akan mengalami peningkatan risiko mortalitas sebanyak 0,06 kali lipat, dan pasien dengan skor ICH $\geq 3$ setidaknya mengalami peningkatan risiko sebanyak 0,3 kali lipat. Hal ini serupa dengan penelitian sebelumnya yang mendapatkan adanya korelasi kuat antara skor ICH dengan mRS (modified rankin scale) pasien, yakni semakin tinggi nilai skor ICH maka semakin tinggi nilai mRS-nya yang menunjukkan 
perburukan luaran pasien. ${ }^{18}$ Dari data didapatkan Nagelkerke $R$ Square sebesar 0,343 yang berarti variabilitas mortalitas yang dapat dijelaskan oleh skor ICH sebesar $34,3 \%$, sedangkan sisanya dijelaskan oleh variabel lain yang tidak termasuk dalam model penelitian. Beberapa di antaranya yang mungkin ialah penyakit penyerta seperti koagulopati, hipertensi, maupun tindakan terapi yang diberikan. ${ }^{2}$ Pasien PIS yang dilakukan terapi operatif lebih sedikit dibandingkan terapi konservatif. Hasil uji analisis antara skor ICH dengan tindakan terapi yang diberikan menunjukkan adanya hubungan yang bermakna (Tabel 5). Berkaitan dengan adanya komponen dari skor ICH yang menjadi salah satu penentuan tindakan terapi pada kejadian PIS, yakni pasien dengan GCS 6-8 di bagian frontal atau temporal dengan volume $>20 \mathrm{cc}$. Syarat lainnya diluar skor ICH berupa adanya pergeseran struktur melewati garis tengah $\geq 5 \mathrm{~mm}$ dan atau kompresi pada sisterna. ${ }^{19}$ Oleh karena itu, setidaknya komponen skor ICH berupa GCS dan volume yang semakin memberat akan mempengaruhi pengambilan tindakan terapi operatif pada pasien. Akan tetapi, hasil analisis antara terapi dengan mortalitas pasien PIS pada penelitian ini menunjukkan hubungan tidak bermakna (Tabel 6). Selain itu, jika dilihat berdasarkan terapinya, persentase pasien hidup yang diterapi secara konservatif paling banyak merupakan pasien dengan skor ICH 0 dan relatif menurun sebanding dengan penurunan skor. Pasien meninggal yang diterapi secara konservatif maupun operatif, paling banyak merupakan pasien dengan skor ICH $\geq 3$. Sampai saat ini tindakan operatif memang masih menjadi perdebatan. Penentuan tindakan terapi yang sebanding dengan peningkatan skor ICH, membuat tindakan operatif menjadi alternatif pilihan yang dapat dilakukan untuk mengatasi pasien dengan skor ICH yang tinggi.

\section{Simpulan}

Dapat disimpulkan bahwa terdapat korelasi yang signifikan dan hubungan positif sebagai prediktor independen antara skor ICH dengan mortalitas pasien PIS di RSUD Ulin Banjarmasin. Saran pada penelitian ini adalah 1) Dapat diaplikasikannya skor ICH sebagai penilaian rutin dalam mempertimbangkan tindakan terapi dan prediksi prognosis pasien, 2) Perlu dilakukan penelitian lebih lanjut terkait perlu tidaknya memodifikasi komponen usia terutama untuk populasi masyararakat Indonesia, 3) Perlu dilakukan penelitian lebih lanjut dengan sampel yangbervariasi(ICHtraumatik) dan datayanglebih lengkap (penyakit penyerta dan onset meninggal).

\section{Daftar Pustaka}

1. An SJ, Kim TJ, Yoon B-W. Epidemiology, risk factors, and clinical features of intracerebral hemorrhage: an update. J Stroke. 2017;19(1):3-10.

2. Hadi J. Pengaruh koagulopati terhadap glasgow outcome scale penderita cedera kepala berat yang tidak mempunyai indikasi operasi [Skripsi]. FK UNAND. Universitas Andalas; 2014.

3. Christensen B. Glasgow outcome scale [Internet]. Medscape. 2014 [cited 2019 Apr 15]. Available from: https://emedicine. medscape.com/article/2172503-overview

4. Qureshi AI, Mendelow AD, Hanley DF. Intracerebral haemorrhage. Lancet. 2011;373(9675):1632-44.

5. Aguilar MI, Brott TG. Update in intracerebral hemorrhage. The Neurohospitalist. 2011;1(3):148-59.

6. Gupta VP, Garton A LA, Sisti JA, Christophe BR, Lord AS, Lewis AK, et al. Prognosticating functional outcome following intracerebral hemorrhage: The ICHOP score. World Neurosurg. 2017;19(2):65-73.

7. Tjoumakaris SI. Intracerebral hemorrhage (ICH) score [Internet]. Medscape. 2014 [cited 2019 Apr 15]. Available from: https:// emedicine.medscape.com/article/2172479overview

8. Aysenne AM, Albright KC, Mathias T, CHang 
TR, Boehme AK, Beasler TM, et al. 24-Hour ICH score is a better predictor of outcome than admission ICH score. 2017;263(2):21927.

9. Hsieh JT, Ang BT, Ng YP, Allen JC, King NKK. Comparison of gender differences in intracerebral hemorrhage in a multi-ethnic Asian population. PLoS One. 2016;11(4):110.

10. Delcourt C, Sato S, Zhang S, Sandset EC, Zheng D, Chen X, et al. Intracerebral hemorrhage location and outcome among interact participants. Neurology. 2017;88(15):1408-14.

11. Ivone J, Supantini D, Haliem HC. Gambaran Penderita Stroke Akibat Perdarahan Intraserebral Di RSUD Prof. Dr. Margono Soekarjo Purwokerto Tahun 2013 [Skripsi]. FK Maranatha. Universitas Kristen Maranatha; 2013.

12. Hegde A, Menon G. Modifying the intracerebral hemorrhage score to suit the needs of the developing world. Ann Indian Acad Neurol. 2018;21(4):270-4.

13. Sunjaya W. Gambaran Intracerebral Hemorrhage (ICH) Score pada Pasien Stroke Hemoragik yang Dirawat Inap di RSUP H. Adam Malik Medan [Skripsi]. FK USU. Universitas Sumatera Utara; 2016.
14. Arifin I, Kaelan Ch, AKbar M, Muis A, Tammasse J, Ganda IJ. Mortalitas pasien strok perdarahan intraserebral menggunakan skor intracerebral hemorrhage (skor ICH) di Makassar [Disertasi]. FK UNHAS. Universitas Hasanuddin; 2014.

15. Rizal A, Faisal A, Dwidanarti SR. Correlation of volume and intracerebral site with hemorrhagic stroke mortality based on CT scan. Acad Hosp J. 2018;1(1).

16. Chan E, Anderson CS, Wang X, Arima H, Saxena A, Moullaali TJ, et al. Significance of intraventricular hemorrhage in acute intracerebral hemorrhage intensive blood pressure reduction in acute cerebral hemorrhage trial results. Stroke. 2015;46(3):653-8.

17. Statistik BP. Data Kalimantan Selatan 2018 (metode baru) [Internet]. Direktorat Analisis dan Pengembangan Statistik. 2019 [cited 2019 Nov 22]. Available from: https://ipm. bps.go.id/data/provinsi/metode/baru/6300

18. Putra F, Frida M, Ahmad B. Hubungan ICH score dengan outcome fungsional (setelah 3 Bulan). J Kesehat Andalas. 2018;7(Supplement 2):21-5.

19. Wali AR, Porras K, Abraham P, Brandel MG, Dieppa DS, Steinberg J, et al. Surgical management of intracerebral hemorrhage. IntechOpen. 2017;13. 